\title{
Energy Policies at Crossroads - Will Europe's 2030 targets and framework be in line with the Paris Climate Agreement?
}

\author{
Rainer Hinrichs-Rahlwes ${ }^{1,2, *}$ \\ ${ }^{1}$ European Renewable Energies Federation (EREF), Brussels, Belgium \\ ${ }^{2}$ German Renewable Energy Federation (BEE), Berlin, Germany
}

Accepted: 4 January 2019

\begin{abstract}
In November 2016, the European Commission presented the Clean-Energy-for-all-Europeans Package. It consists of eight legislative proposals which should define targets and policy and regulatory frameworks for the EU's climate and energy policies up to 2030 and beyond. Recasts of the existing Renewable Energies Directive and the Energy Efficiency Directive, as well as proposals for a new energy market design, which should be fit for renewables, are among the key elements of the package, which aims at replacing the existing 2020framework. The package includes 2030-targets for Greenhouse Gas Reduction (at least 40\%), Energy Efficiency (at least 27/30\%), and the share of Renewables in Gross Final Energy Consumption (at least 27\%). In contrast to the 2020-framework, the EU-wide renewables-target would no longer be underpinned by binding national targets but should be reached in a joint effort with a new governance system. Since the proposal was submitted to the European Parliament and the European Council for the legislative procedures which must end in an agreement before the next elections for the European Parliament in 2019, controversial debates are taking place. The intention is to finalise the legal procedures before the end of 2018. Parliament and Council had planned to decide about their respective opinions about the various pieces by February 2018. Afterwards, probably not finished before the end of 2018, compromise negations will take place, before the whole package will eventually be accepted by both bodies. Among the most controversially discussed topics is the ambition level of the proposals and whether or not it is in line with the commitments signed by the EU and all its Member States in the context of the Paris Agreement. Industry stakeholders not only from the renewable energy sector and environmental NGOs have proposed significantly higher targets in order to stay "well below $2{ }^{\circ} \mathrm{C}$ " of global warming before the end of the century. They also suggested continuing binding national targets or - as a compromise - enacting a very strict governance system. I shall present and evaluate the state of play of the 2030-framework decision process. And I shall end with some policy recommendation still to be considered in the ongoing debate.
\end{abstract}

\section{Introduction}

The European Union and its Member States have been among the pioneers of renewable energy and frontrunners of climate protection. Denmark, Germany, Spain, Portugal, and Austria were among the first countries to successfully accelerate the deployment of renewable energies. Dedicated policies, most of them using feed-in tariffs or feed-in premiums, triggered a significant boost of new renewable energy installations in the power sector resulting in drastic cost reductions, whereas less support was aiming at transport, heating and cooling, industry and other end-use sectors. In these sectors, renewables are developing much slower and will need more supportive

\footnotetext{
* e-mail: rainer.hinrichs@gmx.de
}

policies and frameworks including for sector coupling and system integration, if the rapid decarbonisation of the energy sector is a serious objective of all those who have committed to the Paris Climate Agreement.

Europe has an ambitious and widely effective policy and regulatory framework for renewable energy, energy efficiency and greenhouse gas reduction up to 2020. The 2030 targets and policies are about to be agreed before the end of 2018 and a new 2050-strategy is being developed to bring the EU in line with the climate commitments. Unfortunately, too many Member States have tried to reduce policy ambition and to water down directives and regulations supporting renewables and efficiency, while at the same time preventing effective carbon pricing and continuing to directly and indirectly support fossil and nuclear energy. Some Member States, e.g. France, UK, Poland and their allies are (ab)using the national 
prerogative to define their own energy mix (which is granted by the European Treaties) as a pretext to continue supporting fossil and nuclear energy - irrespective of the fact that renewables (in particular wind and solar) are meanwhile the cheapest sources of energy, even in distorted markets.

At the same time, investment in renewables is significantly decreasing in the EU, whereas other countries, among them more and more developing countries, are significantly extending their quest for a renewable energy transition, with China and some other countries including the United States (despite major interventions from the president in favour of fossil fuels) leading the way in an accelerating race for clean energy for all.

On this background, the European Union and its Member States are developing targets and frameworks for 2030. So far, compromise has been reached on four legislative proposals, whereas four other pieces of legislation are still pending. Compromise results are expected before the end of 2018 or in early 2019, before elections for a new European Parliament would put an end to pending cases for at least half a year. So far, it is encouraging to see that the first four legislative compromises were better than the original proposals from the European Commission and certainly more ambitious than some backwards leaning Member States would have them.

\section{Global development of renewable energy}

Renewables have become mainstream and targets and policies for accelerating their development and deployment are implemented worldwide. Most policies and targets are aiming at the power sector, whereas policies for renewable heating and cooling and renewables in the transport sector are less frequently found. The International Renewable Energy Agency (IRENA) [1] estimates that 10.3 million jobs exist in renewables worldwide in 2016, up $5 \%$ from 2015. 4.2 million people had jobs in solar energy, 3 million in bioenergy, 1.8 million in hydropower, 1.2 million in windpower and 100000 in geothermal energy. ${ }^{1}$

Investment in renewable energy was up again in 2017, after some slowdown in the years before. The Global Policy Network for the 21st Century (REN21) in its Renewables 2018 Global Status Report [2], based on data from Bloomberg New Energy Finance (BNEF), estimates that 280 billion USD (or 320 including large hydropower) were invested in renewables in 2017, up 2.2\% from 2016. Investment in renewables was roughly three times as much as in new fossil or nuclear capacity. In 2017, the balance of investment in renewable energy shifted further towards developing country. Whereas developed countries invested 103 billion USD in 2017 (down from 151 in 2014), developing countries increased investment from 133 billion USD in 2014 to 177 in 2017, with China providing the largest share with 127 billion USD in 2017 (up from 85 in 2014). The Chinese figures are even more impressive when compared to the European Union. China increased

\footnotetext{
${ }^{1}$ Facts and figures in this chapter are from REN21 (2018), if not quoted differently.
}

investment in renewables from 48 billion USD in 2011 via 85 in 2014 to 127 in 2017, while the EU's investment decreased - after an all-time high in 2011 of more than 129 billion USD - via 86 in 2014 to below 41 billion in 2017, which is less than China's investment in 2010.

By end of 2016 (more recent figures are not available), renewable energy provided $18.2 \%$ of the world's final energy consumption (up from $15 \%$ in 2005), out of which 10.4 percentage points came from modern renewables and 7.8 from traditional biomass. The use of traditional biomass is slowly decreasing, while modern renewables have been growing at an average annual rate of $5.4 \%$ since 2005-still too slow for achieving the objectives of the Paris Agreement but going in the right direction. Growth of renewables has been strongest in the electricity sector, with a $26.4 \%$ share of global power production in $2017 .^{2}$ Although the power sector represents only $20 \%$ of global energy consumption, this development is encouraging, because it shows that - based on well designed and effective policies driven by strong political will - necessary fundamental transformation of the energy system is possible. Heating and cooling and transport need to be addressed by decision makers rather now than later.

Growth of modern renewables is a valuable indicator of a country's or a region's or a community's willingness to further the development of sustainable renewable energy and related fundamental transformation of the energy sector. In the last 10 years, global wind capacity increased from $94 \mathrm{GW}$ in 2007 to $539 \mathrm{GW}$ in 2017. $52 \mathrm{GW}$ were added in 2017, with China leading with $19.7 \mathrm{GW}$ newly installed, followed by USA and Germany as distant 2nd and 3rd with $7 \mathrm{GW}$ and $6.1 \mathrm{GW}$, respectively, followed by the UK (4.3 GW) and India (4.1 GW). China also is the lonely champion of overall renewables power capacity with 334 GW, followed by the European Union with 320 GW and the US a distant 3rd with $161 \mathrm{GW}$ and Germany with $106 \mathrm{GW}$ (which is included in the EU's $320 \mathrm{GW}$ ), India $61 \mathrm{GW}$, Japan $57 \mathrm{GW}$ and the UK with $38 \mathrm{GW}$ (also included in the EU's $320 \mathrm{GW}$ ). It goes without saying that China is also the lonely leader of the global solar PV markets with more than $131 \mathrm{GW}$ of installed capacity, out of which $53.1 \mathrm{GW}$ were added in 2017. The US with an overall capacity of $51 \mathrm{GW}$ (10.6 GW added in 2017) and Japan with 50 GW (7 GW added in 2017) are 2nd and 3rd, closely followed by Germany with $42 \mathrm{GW}$ (with only 1.7 GW added in 2017). In terms of new capacity, India was 3rd with $9.1 \mathrm{GW}$ added and nearly doubling capacity in 1 year. China's dominance is even stronger in solar thermal heating with a market share of more than $71 \%$, leaving $3.9 \%$ for the US as a distant 2 nd, followed by Turkey $(3.3 \%)$ and Germany (3\%).

It is obvious that the old champions in Europe (Germany, Denmark and Spain) have found serious competitors (China, but also the US, India and a growing number of developing and emerging economies) in the quest for global leadership of the energy transition.

$\overline{2}$ IEA (2018) [3] has slightly lower figures (25\%), but basically showing a similarly strong and increasing growth of Renewables globally. 
The impressive growth in the champion countries should not overshadow some remarkable and ambitious efforts in smaller and poorer countries. On a per capita base, Iceland and Denmark (and not China and US) are the global champions of installed renewable power capacity (excluding large hydro). On a per capita base, Germany and Japan are the champions of installed PV capacity, instead of China and the US on mere capacity base, followed 3rd by Belgium, Italy and Australia. On a per capita base, Denmark, Ireland and Sweden are the champions of installed wind capacity, followed by Germany and Portugal - leaving GW-champions China and US far behind and leaving Germany on the 4th rank only. In solar thermal for heating, the lonely champion on capacity basis, China, is not even among the top 5 when it comes to per capita ranking, where Barbados, Austria and Cyprus are closely followed by Israel and Greece. A similar difference can be observed, when it comes to annual investment in new capacity. Whereas, in 2017, China, US, Japan, India and Germany were leading new investment in renewables, the top 5 look completely different when assessed per unit GDP. The Marshall Islands are leading this competition, followed by Rwanda, Solomon Islands, Guinea Bissau and Serbia.

The global energy transition is under way, much faster than expected only a few years ago, and it will gain more momentum in the years ahead - and there certainly is no alternative to significantly increasing renewables, if we are serious about limiting global warming to a just tolerable level of $2{ }^{\circ} \mathrm{C}$ (or only $1.5^{\circ} \mathrm{C}$ ) above preindustrialised times - in other words, if we are serious about our commitments under the historic Paris Climate Agreement.

\section{Europe's policies and frameworks for renewables}

The European Union and many of its Member States have been early champions of greenhouse gas reduction and policies for renewable energy. The Kyoto Protocol would not have been agreed on and ratified by the necessary majority of countries without the proactive role of the European negotiators. And it is also safe to assume that the Paris Agreement would not have been possible without a strong role of European countries - but certainly the willingness of China to agree on an ambitious deal was another major condition, as well as the constructive role of the US with the Obama administration in charge.

The EU is trying to maintain high ambition in programmatic objectives and visions. Not only did the EU present decarbonisation scenarios in 2011, which were all in line with ambitious greenhouse gas reduction efforts and all with very high or dominant shares of renewable energy by 2050. When taking office in 2015, the European Commission's President, Jean-Claude Juncker, underlined the ambition to make Europe the global number 1 in renewables. Under his leadership, the EU developed a strategy for an ambitious Energy Union: "The goal of a resilient Energy Union with an ambitious climate policy at its core is to give EU consumers - households and businesses - secure, sustainable, competitive and affordable energy. Achieving this goal will require a fundamental transformation of Europe's energy system" [4].

Europe's positive role in climate negotiations so far is founded on domestic policy objectives - and on an effective energy and climate framework up to 2020, underpinned by continued efforts to maintain a momentum for full implementation of the Paris Agreement in the international political arena. Unfortunately, commitments of European leaders have become less credible, because of a significant slowdown of implementation of agreed policies for renewables and efficiency. European investment in renewables fell dramatically in the last few years to the low levels of more than $10 \mathrm{yr}$ ago. The energy transition is slowing down, and policy discussions about a new framework up to 2030 have not yielded really ambitious objectives and the strong policies needed for implementing the Paris Climate Agreement. The recently opened public consultation ${ }^{3}$ on a strategy for long-term EU greenhouse gas emissions reductions may be an opportunity to increase existing targets and develop new momentum for a more ambitious climate and energy policy - but doubts remain.

\subsection{Towards 2020 - Good framework to be implemented}

Up to 2020 , the EU is aiming at share of at least $20 \%$ renewables in gross final energy consumption (GFEC), at least 20\% efficiency increase and at least $20 \%$ greenhouse gas reduction (or 30\%, if other relevant countries commit to similar objectives). ${ }^{4}$ These objectives are underpinned by differentiated binding national targets for each of the 28 Member States and guided by an indicative trajectory. Target reaching is facilitated by National Action Plans, biannual reporting obligations, a set of voluntary cooperation mechanisms between Member States and with third countries for target achievement, and infringement procedures in case of missing the binding 2020 targets. The national reports are evaluated in a biannual report from the European Commission - meant to point out, if the Union as a whole and each Member State is on track towards the 2020-targets or if additional efforts are necessary.

The most recent Renewable Energy Progress Report [5] shows that target achievement in 2020 cannot be taken for granted. Figure 1 shows the growth of renewable energy in GFEC from $8.5 \%$ in 2004 to $16.4 \%$ in 2015 . More recent figures [6] indicate a share of about $17 \%$ in 2016. Figure 1 also shows the indicative trajectory up to 2020 , which is becoming steeper at the end. And it shows - a little bit above the trajectory - the projected shares of renewables in the National Renewable Action Plans. The European Commission points to the risk of not reaching the $20 \%$

\footnotetext{
$\overline{3}$ https://ec.europa.eu/clima/consultations/strategy-long-termeu-greenhouse-gas-emissions-reductions_en- consultation closing on 8 October 2018.

4 Although the Paris Agreement could certainly be understood as such a commitment, the EU never officially increased the 2020 target from $20 \%$ to $30 \%$ - among other reasons with reference to the ongoing 2030 negotiations.
} 


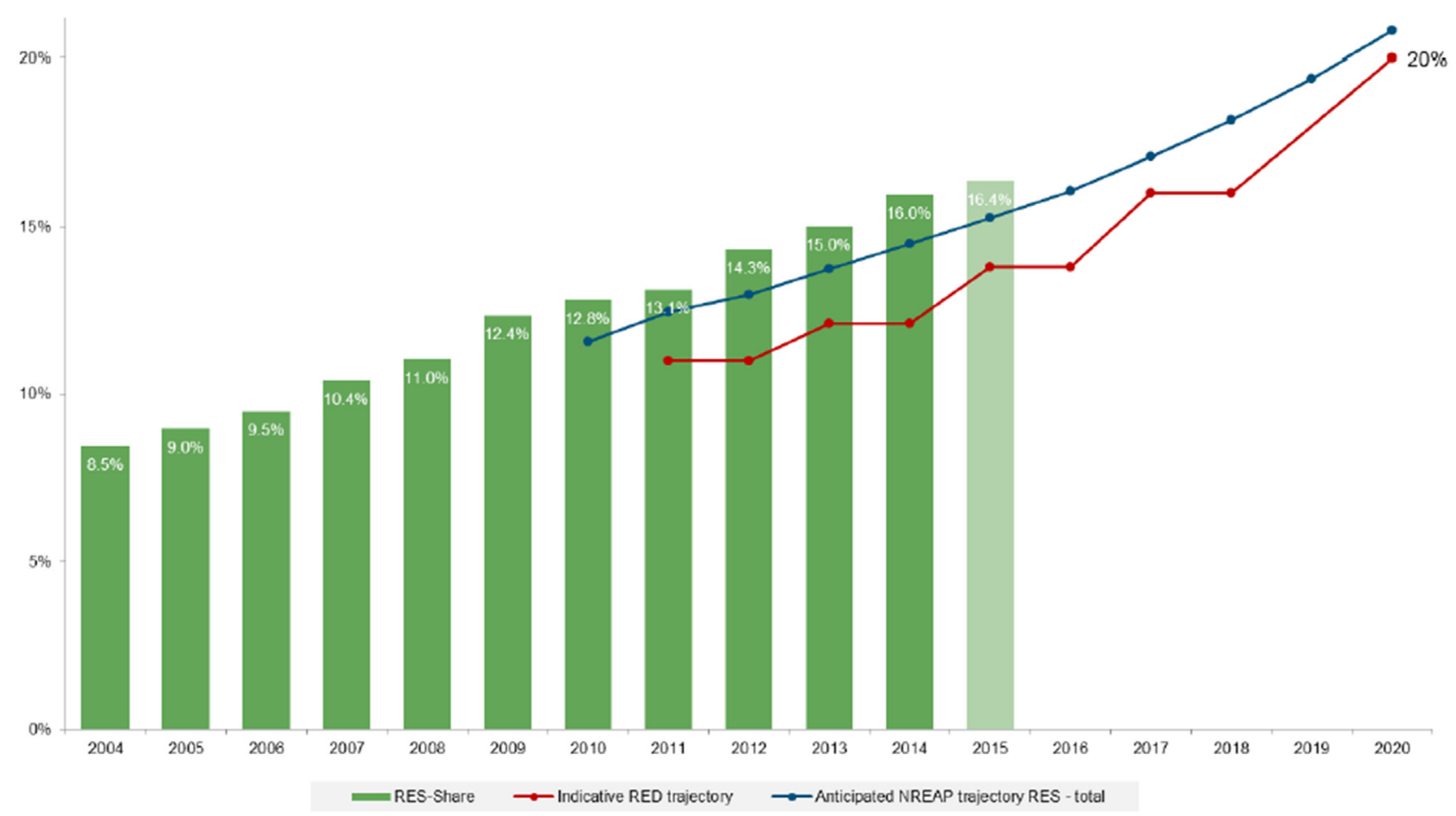

Fig. 1. Renewable energy shares in the EU versus Renewable Energy Directive (RED) and National Renewable Energy Action Plan (NREAP) trajectories (based on EUROSTAT, Öko-Institut). Source: COM 2017 [5].

share in 2020: " $\ldots$ as the trajectory becomes steeper in the years ahead, efforts to keep on track will need to intensify ...". The need becomes more evident when it comes to the different sectors. Whereas renewables are growing slowly but smoothly in the electricity sector, particularly wind and solar, growth is slower in the heating and cooling sector with stagnating deployment since 2013, and in the transport sector with only $6 \%$ achieved so far and no relevant increase since 2011. Experts and industry have voiced their concerns that the 2020-targets may not be reached, including by some of the old frontrunner countries including Germany and Spain. In 2016, 11 Member States had already reached their 2020-targets and 9 were far away with little chance to catch up until 2020 [6].

\subsection{Towards 2030 - Business as usual or implementing the Paris Agreement}

Due to long investment cycles in the energy sector and to long lead times for political decisions, the discussion about a climate and energy policy framework beyond 2020 gained momentum in 2014. First evaluations of the 2020framework showed that more efforts may be needed to achieve the targets, and some Member States advocated for a "more market based" framework towards 2030. Poland and other eastern European countries were opposing any new targets after 2020. The UK, France and others were advocating for a European greenhouse gas reduction target only, opposing specific targets for renewables and energy efficiency and national targets as in the 2020-framework. Their instrument of choice was a "new governance model", which would require national climate and energy plans but would not allow the European Commission to reject them for inadequacy. Others, including Germany, Austria and Sweden underlined their willingness to develop strong targets for greenhouse gas reduction, efficiency increase and renewable energy. They were not very outspoken, however, in terms of defending national binding targets beyond 2020 .

\subsection{European Council Conclusions}

On this background, the European Council (the heads of state and government of all Member States) in October 2014 agreed on a weak position for a 2030 climate and energy framework. They agreed on a domestic greenhouse gas reduction target of at least $40 \%$ by 2030 and at least $27 \%$ renewables and $27 \%$ efficiency increase. The targets were criticised by NGOs for being insufficient for meeting climate targets and by the renewables industry for being hardly more than business as usual and not providing investment security. The Council strongly agreed on not supporting national binding targets and establishing a robust governance model instead, which was still to be defined.

Among the positive elements of the Council Conclusions was the commitment to fully implement the 2020 targets and to develop a new energy market design which should be fit for renewables including a multitude of decentralised producers and consumers.

\subsection{Clean-Energy-for-all-Europeans Package}

Two years later, on 30 November 2016, the European Commission opened the legislative process for a 2030 climate and energy framework. They presented the CleanEnergy-for-all-Europeans Package (also called Winter 
Package) with eight legislative pieces to implement and specify the 2014 Council Conclusions. As required by the European Treaties, the package was submitted to the European Parliament and to the Council. Both institutions need to agree on the Regulations and Directives, before they can enter into force. Given upcoming elections for the European Parliament in May 2019, the process needs to be formally concluded by early 2019 -more than 8000 pages to be read, discussed and agreed.

The Winter Package [7] consisted of proposals for recasts of the Renewable Energy Directive (RED), the Energy Efficiency Directive (EED), the Energy Performance of Buildings Directive (EPBD), for a Governance Regulation (GovR), for a Risk Preparedness Regulation (RPR), for an ACER Regulation and for Market Design (MD) Directive and Regulation. They all needed to be voted in Council and Parliament.

Taking stock of the wide range of proposals, renewable energy and environmental stakeholders saw a mixed picture. On the downside, the low level of ambition of the 2014-Council Conclusions had been kept, as well as the lack of national targets and a meaningful governance proposal. In addition, the proposal required mandatory technology neutral auctions or tenders as the main support scheme for renewable energy and it widely abolished priority access and dispatch for renewables. Only exceptionally and for small installations below $500 \mathrm{~kW}(250 \mathrm{~kW}$ as of 2026), feed-in policies and technology specific support or exceptions from balancing responsibility should be possible after 2020 . Member States should be obliged to increasingly open their auctions to competitors from other Member States. No effective proposals for carbon pricing beyond ailing Emissions Trading System (ETS) or phase-out plans for fossil and nuclear power were included in the package.

On the positive side, the obligation to fully implement the 2020-targets and ruling out retroactive and retrospective changes of support systems were welcomed by the renewables sector. Suggestions for supporting energy communities, consumers and self-consumption were a good basis for further discussions. The intention of creating flexible markets fit for a multitude of decentralised producers and consumers and allowing renewable energies to participate in all market segments are on the positive side, with some need for clarification and improvement. Also, language was welcomed on simplified and transparent procedures and on limiting the use of capacity markets, which more often than not result in significant lock-in of dirty and inflexible fossil capacity.

The renewables industry and environmental NGOs worked hard to support those in the European Parliament who were willing to improve the Winter Package and to work with those national governments which were open for arguments. Apart from biomass related questions, where environmental NGOs asked for very strong sustainability criteria and for limiting and phasing out 1st-generation biofuels, and irrespective of some hesitation on the side of a few of the renewables associations, there was a wide and strong agreement on the key points which needed improvement.

The 27\%-target for renewables in 2030 was based on outdated and much too high cost assumptions for renewables and too low costs for other energy. Many associations reminded policy makers that already in 2011, the renewables industry had suggested a target of $45 \%$ in 2030. The European Wind Association, WindEurope, in the beginning only asked for "more than $27 \%$ ", whereas some others, including important Members of the European Parliament suggested to go for "at least 35\%", which was eventually adopted as the Parliaments position [8] and supported by Renewables Industry and environmental groups as "a bare minimum" of what is needed. Most stakeholders, as a next priority, strongly advocated for continuation of binding national targets, or at least strong benchmarks. A common rulebook for renewables support, including the right for Member States to apply technology specific auctions and tenders and to maintain priority dispatch and access for renewables, as well as exceptions from balancing responsibility, at least for existing installations, was another major request. For the Market Design initiative, flexibility should be the overarching principle allowing for market participation of renewable energy in all segments.

\subsection{Compromise in trialogue negotiations}

When this paper was written, four of the eight legislative proposals had been voted and politically agreed between Parliament and Council. The first to pass was the EPBD, next the GovR [9]. RED and EED were controversial until the 2018 summer break, particularly because of the target discussion. ACER, RPR, MDR and MDD will be decided by end of the year or by early 2019 the latest - after this paper will be finalised.

For EPBD and EED, compromise was found for all major issues. The indicative EU Energy Efficiency target for 2030 was increased from $27 \%$ to at least $32.5 \%$ with an upwards review clause for 2023. A similar increase and review were agreed for the EU-binding 2030 renewables target of at least $32 \%$ [10]. Given the strong reluctance of some Member States to allow for any target higher than $27 \%$, this is a positive development, but with a view to the necessity of adjusting policies to the commitments under the Paris Agreement, it is only a first step.

Apart from the agreement about higher targets, other important points were settled. In contrast to the original proposal, Member States' right to decide whether they chose technology neutral or technology specific support schemes remains in place. Opening of support schemes for other Member States remains an important objective, but it is not mandatory. For giving project developers, manufacturers and investors a reasonable perspective, Member States are required to regularly publish plans for new renewable capacity with a 5 yr visibility. Strong language against retroactive changes of support schemes and for transparent and effective administrative procedures and fees was included.

A highlight of the agreement is support for community energy projects and a basic right for every citizen to produce, consume and sell the energy produced from installations of less than $30 \mathrm{kWp}$ on their own premises, including in third party ownership and in cooperation with others. Member States must not impose burdensome or discriminate procedures and fees or taxes on self-consumption. Consumer 
organisations and the solar industry celebrated this as a breakthrough for more decentralised renewable energy production and strengthening the role of prosumers and potentially ruling out our reducing significantly existing fees and taxes which have prevented a strong development for more decentralised and community owned projects.

The institutions agreed on a $14 \%$ target for the 2030 share of renewables in transport. This objective had been controversially debated, because environmental groups campaigned for exclusion of first-generation biofuels and for stronger sustainability criteria, whereas others suggested more pragmatic solutions. Eventually, it was agreed to cap the maximum share of first-generation biofuels to $7 \%$ with a flexibility for Member States to choose a lower cap and thus reduce the $14 \%$ target. Member States may incentivise waste based and innovative biofuels by multiplying their shares for target achievement, which also applies to renewables in shipping, aviation and rail transport and with up to 3.5 for electric vehicles.

Agreement includes an indicative obligation for Member States to increase the share of renewables in heating and cooling by 1.3 percentage points every year with a $40 \%$ flexibility for waste heat. Clarifications about guarantees of origin will help power purchase agreements to be more easily established and implemented, which an important element for direct corporate sourcing of renewable energy by smaller and larger companies. ${ }^{5}$

\subsection{Markets fit for renewables - creating a level playing field}

After summer break, the remaining four legislative pieces of the 2018 Winter Package will be negotiated. Whereas the RPR will probably pass without much controversy, the ACER regulation will be more difficult to agree on, because Member States have a strong position on not weakening national authorities in favour of a European institution (ACER). It is expected that compromise will be found by agreeing on indicative cooperation mandates instead of increased competency for ACER.

The most important and controversial dossiers will be the Market Design Regulation and Directive (together MDI), which will be the basis for future EU energy markets. Results will have a strong impact on whether or not or how fast energy markets will be a level playing field fit for increasing shares of variable and more decentralised production and consumption including for private and industrial self-consumption.

Although carbon pricing is not a direct part of the MDI, there are elements which are designed to complement the existing ETS. Weak or strong criteria for limiting capacity markets to the absolute minimum and only after having considered cross border capacities based on transparent criteria will impact future decisions of Member States to continue or phase out highly emitting power plants. This is why stakeholders are advocating for strictly limiting capacity markets and why they are strongly defending

\footnotetext{
${ }^{5}$ For more detailed analysis of the compromise see i.a. my opinion piece in reference [11].
}

or trying to strengthen a proposal from the European Commission for Energy Performance Standards (EPS), which would rule out participation of fossil power plants in capacity markets, if they are emitting more than $550 \mathrm{~g}$ of $\mathrm{CO}_{2}$. Poland and other countries with a high share of coal in their energy mix are against any such EPS, whereas NGOs have asked for reducing the value to $350 \mathrm{~g}$. Probably, compromise will be found around the original $550 \mathrm{~g}$ becoming effective later than suggested.

A major step towards a level playing field in energy markets would be removing and phasing out direct and indirect subsidies for unsustainable energy sources. But again, this is not a part of the MDI. Nevertheless, the closer the compromise agreement comes to removing market distortions, the more effectively can it accelerate the energy transition. The objective of MDI is to facilitate participation of all energy sources on a level playing field, which would translate into transforming all energy market segments so that renewables can compete on equal footing.

Renewable energies will have to be allowed and enabled to participate in all sectors of the energy market - futures, day ahead, intraday, balancing, demand response, auxiliary services, etc. This requires shifting energy markets from futures to day ahead and from day ahead to intraday and (close to) real time. Reducing gate closure times to a maximum of 15 minutes, which seems to be a potential compromise within the MDI, would significantly improve opportunities for wind and solar power in these markets. Real time trading would be the next (and parallel) step. Improved forecasts, smarter grids and digitalisation will help opening markets for renewables. Integrating demand response would be another step towards making flexibility the key driver of energy markets.

Until markets are fit for renewables and no longer distorted by direct and indirect subsidies for unsustainable energies, protective measure for renewable energy will need to be continued, e.g. protection for small installations through priority access and dispatch, where appropriate, and by exemptions from balancing responsibilities. Forging compromise in the spirit of creating a really competitive flexible market fit for renewables will considerably accelerate phasing out fossil and nuclear energy and pave the way for a fully renewables-based energy system.

\section{The way forward: towards $100 \%$ renewable energy}

The European Union's ambition to create a resilient Energy Union and to become the world's number one in renewable energy are pointing in the right direction. Recent proposal from the EU-Commissioner for Energy and Climate Action, Miguel Arias Cañete, to increase Europe's greenhouse gas reduction target to at least $45 \%$ by 2030 is another point to be acknowledged. What is missing is decisive action instead of mainly lip-services from European institutions and Member States. If it were not the Paris Agreement that required higher emissions reduction and more clean energy, this summer's record 
temperatures are another incentive to speed up efforts to mitigate climate change. The upwards revision of Europe's renewables and efficiency targets in 2023 is a good step, but there is no reason to wait for 5 years. Evidence is overwhelming.

Europe's 2050 decarbonisation strategy could be another opportunity to increase ambition for the energy transition. Already in 2011, despite outdated cost assumptions and methodology, the European Commission presented roadmaps and scenarios showing that effective decarbonisation by 2050 requires high or dominating shares of renewable energy in all sectors with little or no additional system costs.

Today, renewables are the lowest cost options for new capacity in an increasing number of markets, including where direct and indirect subsidies for fossil and nuclear are still supporting dirty sources. Phasing them out could significantly accelerate the global shift towards renewables, as could higher efficiency standards. Technologies for renewable energy production, smart grids, storage and demand response are available and becoming cheaper at an unprecedented pace.

Given the dramatic cost decreases in renewable energy, particularly in wind and solar photovoltaics, there should be no doubt that increased development and deployment of renewable energy ${ }^{6}$ is the safest and cheapest way towards leaving a liveable planet to future generations. We no longer have to choose whether protecting the environment and limiting global warming is more important than growing the economy or vice versa. Today, it is obvious that the energy transition will create and maintain tens of millions of jobs, avoid societal costs and costs of imported energy sources, grow GDP, generate value and increase energy supply security.

All that is needed is clear and unambiguous political will to implement phase-out strategies for the old system and smart policies for accelerating the transformation towards a $100 \%$ renewable energy system. The sooner and the clearer decision makers embrace the clean energy future, the easier can they make sure not to leave anybody behind.

\section{References}

1. International Renewable Energy Agency (IRENA), Renewable Energy Statistics 2018, Abu Dhabi, 2018. http:// www.irena.org/publications/2018/Jul/Renewable-EnergyStatistics-2018

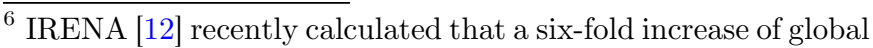
investment in renewables would be necessary to likely limiting global warming to a maximum of $2{ }^{\circ} \mathrm{C}$ or even $1.5^{\circ} \mathrm{C}$.
}

2. Renewable Energy Policy Network for the 21st Century (REN21), Renewables 2018 Global Status Report, Paris, 2018. http://www.ren21.net/wp-content/uploads/2018/06/ 17-8652_GSR2018_FullReport_web_final_.pdf

3. International Energy Agency (IEA), Global Energy \& CO2 Status Report 2017, March 2018, Paris, 2018. http://www.iea. org/publications/freepublications/publication/GECO2017.pdf

4. European Commission, Energy Union Package. A Framework Strategy for a Resilient Energy Union with a Forward-Looking Climate Change Policy, Brussels, 2015. https://ec.europa.eu/ energy/sites/ener/files/publication/FOR\%20WEB\%20energyu nion with\%20 annex en.pdf

5. European Commission, Renewable Energy Progress Report, COM (2017) 57 final, Brussels, 2017. https://ec.europa. $\mathrm{eu} /$ transparency/regdoc/rep/1/2017/EN/COM-2017-57F1-EN-MAIN-PART-1.PDF

6. Eurobserver, The State of Renewable Energies in Europe, 2017 Edition, Brussels, 2018. https: / www.eurobserv-er.org/ category/barometer-2017/

7. European Commission, Clean Energy for all Europeans, Legislative Package, Brussels, 2016. https://ec.europa.eu/ energy/en/topics/energy-strategy-and-energy-union/cleanenergy-all-europeans

8. European Parliament, MEPs set ambitious targets for cleaner, more efficient energy use, Brussels, 2018. http://www.europarl. europa.eu/news/en/press-room/20180112IPR91629/meps-setambitious-targets-for-cleaner-more-efficient-energy-use

9. Council of the European Union, Interinstitutional File 2016/ 0307 (COD), 10307/18, Proposal for a Regulation of the European Parliament and of the Council on the Governance of the Energy Union, amending Directive 94/22/EC, Directive 98/70/EC, Directive 2009/31/EC, Regulation (EC) No 663/2009, Regulation (EC) No 715/2009, Directive 2009/73/EC, Council Directive 2009/119/EC, Directive 2010/31/EU, Directive 2012/27/EU, Directive 2013/30/ EU and Council Directive (EU) 2015/652 and repealing Regulation (EU) No 525/2013-Analysis of the final compromise text with a view to agreement, Brussels (2018a)

10. Council of the European Union, Interinstitutional File 2016/ 0382 (COD), 10308/18, Proposal for a Directive of the European Parliament and of the Council on the promotion of the use of energy from renewable sources - Analysis of the final compromise text with a view to agreement, Brussels (2018)

11. R. Hinrichs-Rahlwes, Das EU-Winterpaket ist besser als befürchtet, aber es reicht nicht, Berlin (in German only), 2018. https://background.tagesspiegel.de/das-eu-winterpa ket-ist-besser-als-befuerchtet-aber-es-reicht-nicht/?utm_cam paign $=$ Background\&utm_medium $=$ Email\&utm_source $=$ Tagesspiegel_Newsletter

12. International Renewable Energy Agency (IRENA), Perspectives for the energy transition: Investment needs for a lowcarbon energy system, March 2017, Abu Dhabi, 2017. https://www.irena.org/publications/2017/Mar/Perspectivesfor-the-energy-transition-Investment-needs-for-a-low-carbonenergy-system 